\title{
Seeking Directions for Multicultural Education for Prospective Pastors in the Korean Multicultural Society
}

\author{
Jae Dong Hwang ${ }^{1}$ \\ ${ }^{1}$ Lecture professor, Department of Multicultural Education, Graduate School of Education, \\ Gwangju National University of Education, South Korea, jaedonghwang@hanmail.net
}

\begin{abstract}
The purpose of this study is to find the direction of multicultural education for prospective pastors of multicultural society through investigating the status of multicultural education at the seminary, a training institute for future pastors. For the data collection, six professors with experience in multicultural education at the graduate school of theology from March 2018 to July 2019 were subjected to in-depth interviews. This study analyzed the result of in-depth interviews through the triangulation method of Guba \& Lincoln (1981) to find the ways to improve multicultural education. The current state of multicultural education at the seminary is not conducted practically and comprehensively. Some aspects of multicultural education were focused on the definition or theory for multicultural. Also, there is no field trip nor internship system, and it is not linked to multicultural education and field in which they are engaged. Based on the results of the study, the following suggestions were made: First, for the proper direction of the direction of multicultural education, the curriculum should be reformed. Second, multicultural theories and sites should be incorporated. Third, multicultural experiences should be provided. Fourth, a sense of calling through networking should be formed. Fifth, external environments for multicultural education should be provided.

The findings of this study is intended to help the practical and detailed multicultural education for prospective pastors, and to understand migrants and multicultural missionary work in terms of healing wounds and pains.
\end{abstract}

Keywords: Multicultural Society, Prospective Pastor, Multicultural Education, Multicultural Recognition

\section{Introduction}

To begin with the influx of foreign workers, married immigrants, foreign students, returnees, refugees, and North Korean defectors surpassed 2.45 million in South Korea[1]. Although it is inevitable to live with various immigrants as members of society, many people still have negative perceptions of them. Therefore, to achieve positive changes for a multi-cultural society, it is necessary to improve multicultural awareness[2]. The central government enacted the multi-cultural Family Support Act in 2008 to help multi-cultural families in various ways, and many ministries are working together to improve multicultural awareness. However, such understanding of improvement must be made in multiple areas, and the government's effort must be increased. The improvement of multi-cultural awareness at the spiritual level also must be considered.

In Protestants, the interest in multi-cultural education is increasing, such as using the term "multicultural religious education," which combines the concepts of religious education and multi-cultural

* This article is a re-study of part of a doctoral thesis.

Received: January 22, 2021; 1st Review Result: March 09, 2021; 2nd Review Result: April 26, 2021

Accepted: May 25, 2021 
education[3]. Multi-cultural religious education can be said to be "an effort to develop multi-cultural knowledge, attitudes, values, and skills in the process of learning the Protestant faith." In other words, multi-cultural religious education is regarded as religious education conducted in a multi-cultural society. This is in line with multi-cultural education in various fields.

In particular, the church is a small multi-cultural society where people from different places are gathered together. The church is a suitable place to improve multi-cultural awareness through multicultural education, and pastors should be the center of the education. According to the Bible, 'education' is one of the responsibilities of the pastors. Considering this, it can be said that the role of the pastor is very important for enhancing multi-cultural awareness[4].

So, to improve it at the religious level, a pastor, who is at the center of multi-cultural religious education, is required to possess the proper multi-cultural perceptual accuracy. In addition, it is necessary to create an environment with appropriate competencies, so that proper multi-cultural education can be achieved. Nevertheless, preparations for the multi-cultural society of the Korean church have not been made.

Therefore, it is necessary to produce a pastor who can deal with a multi-cultural problem and can lead a multi-cultural society in this era with multi-cultural capabilities. Thus, this study is conducted to find the direction of multi-cultural education for preparatory pastors by going through the realities of multicultural education. This will be done through in-depth interviews, and analysis of professors who are lecturing at Protestant universities.

\section{Pastor's Multi-cultural Education}

Multi-cultural education has generally been treated as a welfare level education that helps marginalized groups such as migrant workers, marriage immigrants, refugees, and international students. However, the emergence of multinational corporations following globalization emphasizes multi-cultural situation, language competence, and the level of improved education[5]. In order to educate to understand cultures, the environment for the education must be created and educational contents which can deal with education must be provided. That multi-cultural education starts from diversity of cultures. In different words, the purpose of multi-cultural education is to eliminate prejudice, and discrimination against other cultures, and to bring out a change in perception of differences. Banks (2008)[6] stated that multi-cultural education gave opportunities of learning about ethnic groups, races, social classes, genders, and cultural groups. It was defined as an educational reform movement to change educational institutions such as schools.

Moreover, Bemmett (2007)[7] defined multi-cultural education as a teaching-learning approach method that culturally recognizes cultural pluralism in a multi-cultural society based on democratic beliefs.

In a diversified democratic society like the United States, it is emphasized that the purpose of public education is to help all students develop intellectual, social and personal development to maximize their potential. The basic concept of multi-cultural education is an effort to provide equal educational opportunities to all people regardless of ethnicity, race, gender, social class, etc., such that educational institutions must prepare an environment so that students can experience educational equality.

In addition, as a result of multi-cultural education, people should abandon prejudice, and discrimination against other groups. They should take importance on mutual understanding and equal relations with those belonging to other groups. From this point of view, multi-cultural education is an act of helping people to have the proper multi-cultural awareness and at this point, the right multicultural awareness requires an open attitude toward oneself, other cultures, ethnic groups, and genders for acknowledging and accepting individual diversity[8]. 
Nowadays, it is argued that multi-cultural awareness should not be limited to the cognitive aspect, but should be expanded to a practical part capable of receptivity, absorption, attitude, and problem solving. For example, Jung Ji-Hyun, Kim Young-soon, and Hong Jeong-Hoon[9] stated that multi-cultural awareness contains the concept of an active practical dimension to act critically to create a multi-cultural society and to improve the correct perception of the surrounding people.' Since individual perception is an essential factor that determines the person's posture, it is crucial to have the right perception at first to lead to correct behavior. Likewise, important pastors who practice multi-cultural education should also have correct multi-cultural awareness.

For Protestantism, while actively helping multi-cultural people, who are socially underprivileged, on the other hand, there is a dualism about multi-cultural. As an example, prejudice against other people due to the religious characteristic of serving one god[10]. In addition, if one has negative perceptions about other cultures, it is very difficult to change them to be positive. So it is necessary to help them get the correct multi-cultural awareness first. To build the right perception, the Protestant graduate schools of theology is the institution, where educates pastors can help them to form correct multi-cultural awareness. The reason for this is that the multi-cultural education implemented in graduate schools of theology has an impact on the proper awareness of various cultures and cultivation of multi-cultural education capabilities of the preparatory pastors. It means that in the future, they will become promote pastors with correct multi-cultural grasp and multi-cultural education efficacy. Therefore, education should be conducted under a systematic curriculum for students to attend the seminaries. It-is expected to lead pre-pastors to possess correct multi-cultural awareness, multi-cultural education capabilities, and multi-cultural education efficacy.

As our society gets to be a multi-cultural society, the church needs to understands coexistence with multi-cultural members as the God's command and mission. In this way, when we coexist and communicate with multi-cultural members in various ways or when minor conflicts are faced, it will be possible to overcome those with the love of God without hypocrisy. It means that Christians should pursue a life that properly leads the vested interests to the right way and protects the underprivileged. From this perspective, proper understanding and fair consideration for the needy and members of various cultures would be the right attitude to live as a disciple of Jesus.

\section{Method of Research}

\subsection{Participants on this Research}

This study was conducted to find the direction of multi-cultural education for prospective pastors in a multi-cultural society through the realities of multi-cultural education in graduate schools of theology. Participants were subjected to in-depth interviews with 6 professors who had experience of teaching at theological universities and graduate school of theology. The method of the research was conducted one of the most qualitative ways, case study. This was because case study is suitable research ways to analyze their experiences on the subject through various cases. The triangulation method of Guba \& Lincoln (1981) were used to review.

The personal information of those who participated in the study is shown below [Table 1].

[Table 1] Personal Information of Research Participants

\begin{tabular}{|c|c|c|c|c|c|c|}
\hline Division & Gender & Age & Area & Career & Education & Job \\
\hline $\begin{array}{c}\text { Research } \\
\text { Participant 1 }\end{array}$ & Male & 50 's & Seoul & 18 years & Doctor & $\begin{array}{c}\text { Professor of Biblical Studies } \\
\text { Theological University }\end{array}$ \\
\hline $\begin{array}{c}\text { Research } \\
\text { Participant 2 }\end{array}$ & Male & 60 's & Incheon & 26 years & Doctor & $\begin{array}{c}\text { Professor of Humanities and Social } \\
\text { Sciences }\end{array}$ \\
\hline
\end{tabular}




\begin{tabular}{|c|c|c|c|c|c|c|}
\hline $\begin{array}{c}\text { Research } \\
\text { Participant 3 }\end{array}$ & Male & 60 's & Ansan & 25 years & Doctor & $\begin{array}{c}\text { Professor of Multicultural } \\
\text { Chemistry, Director of } \\
\text { Immigration Center, Pastor }\end{array}$ \\
\hline $\begin{array}{c}\text { Research } \\
\text { Participant 4 }\end{array}$ & Male & 50 's & KimPo & 16 years & Doctor & $\begin{array}{c}\text { Representative of the Foreign } \\
\text { Workers Support Center, } \\
\text { Professor of Policy Graduate } \\
\text { School of Damun Chemistry }\end{array}$ \\
\hline $\begin{array}{c}\text { Research } \\
\text { Participant 5 }\end{array}$ & Female & 50 's & Daejeon & 16 years & Doctor & $\begin{array}{c}\text { Professor of Biblical Studies } \\
\text { Theological University } \\
\text { Research Participant }\end{array}$ \\
\hline $\begin{array}{c}\text { Research } \\
\text { Participant 6 }\end{array}$ & Female & 60 's & Honam & 21 years & Doctor & $\begin{array}{c}\text { Professor of Humanities and Social } \\
\text { Sciences Research Participant }\end{array}$ \\
\hline
\end{tabular}

As shown in [Table 1] above, there were 6 participants, and consisted of experts from Seoul, Incheon, Gyeonggi, Ansan, Gyeonggi, Gimpo, Daejeon, and Honam Gwangju. There were 4 males and 2 females, whose ages were varied among the 50s and 60s. In addition, all of them had more than 16 years of experience in multi-cultural education, and achieved doctoral degrees. Looking at the careers of them, there are professors of seminary colleges, pastors, heads of immigrant centers, and representatives of NGOs, are currently engaged in various multi-cultural education at schools as lecturer.

Data were collected by in-depth interviews through 2 to 3 times for each individual, and consent forms for participations were prepared before the interviews. Each Interviews were more than 1 hour in a nice place and the interviews were recorded after obtaining permissions from the participants.

Interview data were transcribed using a Korean document program, and the contents derived for each topic were analyzed. In order to verify whether the contents of the meaning derived as a result were correctly assigned.

It had clearly been explained to the participants that the analyses of the interviews would not to be used for any other purposes but only academic research. In addition, the personal information, names of the participants were indicated as a pseudonym of researcher 1.2.3.4.5.6

\section{Results}

\subsection{Curriculum Re-organization}

Korean society is about to enter a multi-cultural society, and the social change of multi-cultural will require the pastor's principle to be changed. It is necessary for Protestant pastors to improve their multicultural awareness through appropriate multi-cultural education. On the way of entering multi-cultural society, multi-cultural education is a meaningful movement. However, if multi-cultural education stays in an indirect form, it will probably be challenging to achieve the real purpose of multi-cultural education.

"To my conclusion, most of educational institution for the prospective pastors doesn't fully and appropriately provide their students with multi-cultural education. It is not only a difficult from the curriculum of semester but also low level of recognition to the importance of studying multi-cultural situation. Actually, we have only two subject during semesters, such as 'Culture and Korean Society Nowadays', 'Mission and Changes of Society'. What is the matter worse is the quality of the contents which deal with the contents not in regard with real and practical situation but only with the theoretical and theological material. Therefore, I urge that the graduate school of theology provide them with the subjects and curriculum that consist of multi-cultural situations and phenomena which they will face with." (Expert A)

"As mentioned before, even though professors and faculties understand the importance of multicultural society and education, there are many factors that they have to solve, such as absence of experts, 
contents to deal with, and too many subjects which the students must be classified in 4 or 6 semesters, and so forth." (Expert B)

"For the curriculum of multi-cultural education, the first semester of the class would be focused on fundamental theories. It is conducted to obtain multi-cultural awareness and understand immigrants. After that, professional ideas will be taught. For instance, what are E9 and F6, or what are the multicultural acts, etc. Lastly, learners are needed to participate in the natural fields by themselves so that field trips or internships should be added to the curriculum." (Expert C)

"Faith is talking about compassion for people. Therefore, the question of whether prospective pastors have a multicultural perception of living with migrants seems to be higher than that of the general public." (Expert D)

"In the case of pastors, not only are they interested in the members of the church, but they are also interested in evangelizing others to the church. From this point of view, prospective pastors who will serve in the future will also have a high level of interest in others, and considering that Korea is entering a multicultural society, the awareness of multiculturalism is naturally high." (Expert E)

"In my opinion, the graduate school of theology still does not really know the importance of multicultural education. Since, not only for this reason, it has not established any classes related to multicultural education, but also there is not even one professor for this field. It is wondered that graduate school of theology, providing only theology lectures, is able to improve the awareness of multi-cultural perspectives." (Expert F)

In order to improve multi-cultural awareness of Protestant pastors, appropriate multi-cultural education needs to be provided, and for this, the curriculum of the graduate school of theology needs to be reorganized. In other words, it is necessary to prepare a systematic curriculum to help understanding multi-cultural by carrying out theoretical education related to multi-cultural, and to have a confidence that multi-cultural education can be performed in actual field through experiential learning.

I believe that multi-cultural education is not sufficiently implemented at many training institutions. This is because there are difficult situations to avoid in the curriculum where people have to learn a variety of subjects related to multi-cultural education, also the importance of the awareness is still low.

For example, the curriculum of the school where I was working, the subjects were about 'Culture and Modern Korean Society' and 'Mission and Social Change'. This also does not deal with specific content related to multi-cultural education. So it is difficult to find a subject that can learn multi-cultural society and phenomena in the current graduate school of theology. Therefore, it is considered to develop and open classes related to multi-cultural in the future." (Expert J)

Based on the responses of the subjects, all experts insist on the establishment of a multi-cultural curriculum at the Graduate School of Theology to promote multi-cultural awareness and efficacy of Protestant pastors. In other words, there is a need for prospective pastors to complete more systematic and diverse multi-cultural education. As mentioned earlier, pastors should also take the role as teachers. To do so, it is necessary to know multi-cultural and proper multi-cultural awareness. In addition, based on the understanding of the main concepts of multi-cultural education programs, their principles, and related theories, pastors must be able to handle (must handle) correct multi-cultural ministry in the actual pastoral field[11][12]. From this point of view, it can be said that the establishment of a multi-cultural curriculum for the graduate school is essential.

\subsection{Integration between Theory and the Field}

In order to fulfill multi-cultural education, recognizing how much abilities one has is more important than how much one knows of it. Therefore, the reorganization of the curriculum needs to put significance on practical aspect rather than on the theory. In other words, it is necessary for prospective pastors to experience the real field, or participate in internships with the theoretical knowledge related to multi- 
cultural. It is expected to provide an opportunity to feel the real lives of migrants and to internalize them.

It is emphasized that multi-cultural education keeps importance on the theory and the field. It is necessary to work on theologicalization that can be applied to the Korean situation of multi-cultural and theological area. In the bible, there are many examples of multiple culture, which proves that peaceful coexistence with the people (citizens) of God.

"Based on the understanding of this, it is needed to find how to connect the institutions and multicultural people. The contents of both theory and practice can be done in two semesters. Looking up the curriculum for 15-16 weeks of one semester, based on textbooks, it would be great if multi-cultural awareness would be improved through education where it can be practiced." (Expert A)

"I think the curriculum of the graduate schools of theology is not limited to theory. Still it is necessary to experience the field in practical terms, to meet real migrant women, migrant workers, refugees, international students, and North Korean defectors. It is expected to provide experiences that lead them to realize the difference with multi-cultural people." (Expert B)

"To improve multi-cultural awareness, the curriculum of the graduate schools of theology needs to be changed. In other words, it is necessary not only to open theoretical classes related to multi-cultural, but also to provide various programs to experience the field or to experience internships. Furthermore, subjects such as understanding multi-cultural policies should be opened to recognize the necessity of multi-cultural." (Expert C)

In order to increase the multi-cultural awareness of Protestant pastors, the curriculum of the seminary should not be limited to a theoretical approach, but it is necessary to experience the field of ministry which is expected to help them to internalize various knowledge and skills based on what they would experience. In addition, to let them convey effectively, a methodological approach this should be made after all these. At the end, an evaluation should be made on whether education through the curriculum has been effectively implemented.

\subsection{Providing with Variety of Educational Experiences}

In order to enhance the multi-cultural efficacy of Protestant pastors, it is necessary to help them to experience various fields related to multi-cultural situation. To increase the effect of particular action, it is necessary to have an experience of the action before. In other words, to enhance the multi-cultural efficacy of future pastors, it would be the most effective method for prospective pastors to go out to interact with multi-cultural people as an education of multi-cultural.

"As described above, I believe that to increase the sense of multi-cultural efficacy, specific classes should be conducted by setting various multi-cultural situation for particular examples, which are about how to deal with multi-cultural families when they ask help. Courses should be designed by setting multiple problems that may occur at the missional field in Korea, rather than educating foreigners to dispatch them overseas. This education cannot be done only in one semester. Multi-cultural courses should be conducted in conjunction with other classes. Taking liturgics as an example, it is in the subject of practical theology. This type may be given a task-oriented class to lead worship to all members related to multi-cultural awareness. In addition, it would show the students to visit and give services to multicultural families. The educational experience at graduate schools of theology can be varied depending on the curriculum." (Expert A)

"It is the most important, whether direct or indirect, to make good use of the media rather than academic approach.” (Expert B)

"As mentioned above, the key is to have a lot of multi-cultural experiences. The easiest way to do this is to have such an experience on campus. First of all, you will be able to experience various cultures through meeting with foreign students. But more important than this is to meet the migrants who are now settled in Korea and hear the experiences of the native peoples living with them. The best place for 
such an experience would be to find various multi-cultural ministries that are in charge of multicultural ministry and related work. Through this, you will be able to experience the reality and prospects of Korean society at the same time, even if you do not do such ministry on yourself, and you will gain insight into the ministry that you will be responsible for in the future. The best way is to visit various overseas mission fields. Whether in the West or in Asia, there are few places that do not experience a multicultural society. I think that going to such a mission field and experiencing a multicultural society will greatly help in understanding the situation and attitude of immigrants in Korea." (Expert C)

"I remember a student who took my class last year, and that student was closed at the beginning of the class. He had a very negative perception of anger. But after taking the class positive perception of multiculturalism was formed. That's why I'm educated I think it's important. The higher the educational level is, the greater the educational experience is. (Expert D)

The most important thing is, whether it is direct or indirect, that they can build up experiences. Also, it is needed to use the media rather than academic study alone." (Expert E)

I think there should be a place where migrants come to study and communicate with others. It would be a great opportunity for students to experience multi-cultural in the school. By visiting the pastors, carrying out multi-cultural ministry, they can go through the reality of multi-cultural church outside of the school."

To change the awareness of multi-cultural of Protestant pastors in the right direction, various experiences related to multi-cultural are essential to help prospective pastors. Having experiences in multi-cultural fields is the condition that must be achieved through reorganization of the curriculum as described above. However, it is also a good experience various culture for future pastors to collect foreign students to graduate schools of theology. Therefore, it is necessary to invite prospective pastors to multi-cultural centers or churches that are in charge of multi-cultural ministry so that they can directly experience the hospitality for multi-cultural people. The development of multi-cultural competencies is the main purpose of multi-cultural education[13]. In other words, those who are living in a multi-cultural society need to be ready with multi-cultural capabilities to recognize differences with others and respect them, which can be achieved through education.

\subsection{Promoting a Sense of Vocation through Networking}

To enhance the multi-cultural efficacy of Protestant pastors, positive networking should be established. It is necessary to promote a sense of vocation as a pastor. Expert B and Expert E pointed out that an incorrect group culture was formed in the graduate school. It is expected that this hurts the multi-cultural efficacy of Protestant pastors.

"First of all, we need to broad the point of contact by making people interested in multi-cultural, and to increase multi-cultural efficacy, we need to help them do by themselves rather than to force them to do so. Once again, I think that multi-cultural efficacy will only increase when one inspires a sense of ministry vocation to a multi-cultural society." (Expert B)

"As I just said just before, in graduate schools of theology, there is a collective culture among students. That's why they emphasize each other's friendship and closeness. Due to the nature of the graduate school of theology, I think it is very vital to maintain this intimacy. This is because there is a high probability of meeting each other as a co-worker after they graduate. However, inside of them, the need for power takes place behind homogeneity, which is a huge problem. In other words, this culture which forms a powerful collective culture, is not a culture with pure intentions. It is more likely to oppress and harass the weak, such as juniors, and adversely affects graduates on the multi-cultural efficacy. Therefore, in order to enhance the multi-cultural effectiveness of seminary graduates, it is necessary to lead this power-type group culture to positive direction." (Expert E)

The collective culture formed in graduate schools of theology as described above can negatively affect 
the perception of multi-cultural among prospective pastors of Protestant churches[14]. It will be helpful to emphasize the importance of social network theory arguing that social capital induces members' specific actions and exerts various effects on individuals within the social structure. Therefore, if the correct group culture is formed, the members of the group will be positively influenced. From this point of view, various information and experiences related to multi-cultural church are shared within graduate schools of theology, and the need for multi-cultural ministry. If we can explain and inspire their sense of vocation, it will lead them to experience positive changes in multi-cultural awareness as well as enhancing multi-cultural efficacy.

\subsection{Preparation of External Environment}

To enhance the multi-cultural efficacy of prospective pastors, it is necessary not only to insist on the change of future pastors, but also to change the external environment. In other words, it is required to make efforts to find the imperativeness of multi-cultural education through legalization. At the same time, it is necessary to reconsider the quality of multi-cultural education instructors[15].

"Currently, there are so many instructors in multi-cultural education. But when I met a professional instructor, I was surprised. He was pretended as a professional expert, but when we talked about multicultural, he didn't have any knowledge of multi-cultural awareness. To encourage the multi-cultural efficacy of prospective pastors, it is important to introduce a variety of programs, as everyone says. Still, instead of that, I think it is necessary to consider the quality level of instructors at the very first.

"First of all, I think legalization should be done. In the past, even as for the perception of women's ordination, there was a change in perception just after ordination eventually became legal. Likewise, to eliminate prejudice against multi-cultural and emphasize equality, I think it is necessary to have laws and institutions at first." (Expert A)

At present, there is an argument that the qualitative improvement of the multi-cultural education instructors of the graduate school of theology was necessary. Revitalization of multi-cultural education is also important, but the quality of instructors performing multi-cultural education must be improved together. In addition, Legalization is essential to increase the awareness of multi-cultural among the prospective pastors as legalization has improved perception of women's ordination and the efficacy of female pastors has been raised.

\section{Conclusion}

This study focused on the problems arising from the rapid entry into a multicultural society in the religious world.

Therefore, the multicultural education of the seminary and the direction of multicultural education prospective pastors in a multicultural society were investigated. To this end, from a result of in-depth interviews with professors at the graduate school of theology who are pastoring and analyzing them, the following results were derived[16].

First, the current state of multi-cultural education in graduate schools of theology is that the curriculum for multi-cultural education is not properly implemented. Some lectures related to multicultural education put more values on the definition and theory of multi-cultural. Moreover, there is no opportunities of field trip or internship system because no connections are provided between multicultural education and the actual fields. Therefore, the right direction of multi-cultural education for prospective pastors should be established and the curriculum should be reorganized. Prospective pastors should be able to do the right multi-cultural ministry in the pastoral field based on their knowledge of the main concepts, principles, and theories of multi-cultural education. Multicultural education should be taught from a hospitality theological perspective. 
Second, the multi-cultural theory and practice in the field should be connected. Prospective pastors should learn theoretical knowledge about multi-cultural, and carry out to experience the real field, or participate in internships to give them an opportunity to feel the real lives of multi-cultural people and to internalize them[17].

Third, multi-cultural experiences should be provided. It is necessary to help prospective pastors to be exposed in the field related to multi-culturalism and experience multi-cultural education. In most seminary schools, multicultural education is not provided, and even if it is provided, it is only superficially dealt with. Therefore, in order to enhance the multicultural efficacy of prospective Protestant pastors, the curriculum of the seminary has been reorganized to provide theoretical education to help knowledge understanding and experiential education to provide practical multicultural education.

Fourth, it is necessary to develop a sense of vocation through networking. If prospective pastors can explain the imperativeness and raise their sense of work, it will lead them to multi-cultural awareness as well as enhancing multi-cultural efficacy[18].

Fifth, it is necessary to provide external environments. Legalization was essential to enhance the quality of multi-cultural education instructors to increase the awareness of multi-cultural for prospective pastors.

\section{References}

[1] Immigration Policy Headquarters, Korea Monthly Statistics, Ministry of Justice, October, (2019)

[2] S. M. Kim, Y. S. Kim, Understanding Multicultural Education, Korean Cultural History, (2008)

[3] J. S. Park, Korean Protestant Churches' Understanding of and Responses to Multicultural Phenomena, Journal of Religion and Culture, (2010), Vol.14, pp.83-110.

[4] S. Y. Kim, An integrated study on the perception of multicultural education of Korean Protestant pastors, Inha University, Doctoral Dissertation, (2014)

[5] J. N. Seo, The Roles and Challenges of Multicultural Education for the Community Integration in Korea, Journal of Education \& Culture, (2009), Vol.15, No.2, pp.75-104, DOI : 10.24159/joec.2009.15.2.75

[6] J. A. Banks, An Introduction to Multicultural Education, Boston: Pearson, (2008)

[7] C. I. Bennett, Comprehensive multicultural education: Theory and practice (6th ed.), Allyn \& Bacon, (2006)

[8] Y. J. Jo, The Effects of Perceptions of Multiculture on Efficiency Esteem of Multiculture in Elementary School Students, Journal of Korean Practical Arts Education, (2010), Vol.23, No.3, pp.43-58, UCI : G704-000635.2010.23.3.013

[9] J. H. Jeong, Y. S. Kim, J. H. Hong, A Study on Multicultural Recognition of Secondary Students Participating in the Multicultural Literacy Program, The Journal of Yeolin Education, (2014), Vol.22, No.2, pp.19-41, UCI : G704001282.2014.22.2.014

[10] S.Y. Kim, Y. H. Oh, A Study on Recognition about the Multicultural Education of Korea Protestant Minister - Focusing on Seoul, Gyeonggi-do and Incheon - , The Journal of the Korean Association for the History of Religions, (2013), Vol.72, pp.207-235, DOI : 10.21457/kars..72.201309.207

[11] Y. S. Kim, Citizens' Humanities for Multicultural Society; Multicultural Society and Citizen Education: Focusing on Multicultural Competencies, Citizen and Humanities, (2010), Vol.18, pp.33-59.

[12] Y. S. Kim, An integrative study of the Korea protestant ministers' perception on the multicultural education, Inha University Graduate School, Doctoral dissertation, (2014)

[13] S. J. Kim, A Literature Review of the Effects of Culture in Parents' Child-Rearing Behaviors in Divergent Cultural Contexts, The Korean Journal of Human Development, (2015), Vol.22, No.4, pp.1-19, DOI : 
10.15284/kjhd.2015.22.4.1

[14] S.Y. Ahn, W. S. Jang, Korea Youth Panel Survey (KYPS) VII: Factors affecting career types after high school graduation, Korea Youth Policy Institute Research Report, (2009), pp.3-75.

[15] Y. S. Kim, The humanities of multicultural society and coexistence, DB Books, (2018)

[16 Y. S. Kim, M. J. Lee, A Study on the Practical Competence and Function of Multicultural Education Specialist, Multicultural Education Studies, (2010), Vol.1, No.1, pp.77-94.

[17] Y. S. Kim, Multicultural education for the first time, North Korea, DB Books, (2017)

[18] S. Y. Kim, A Study of an Attitude on the Multicultural Education of Protestant Ministers - Focusing on Seoul, Gyeonggi-do and Incheon -, Journal of Education \& Culture, (2016), Vol.22, No.3, pp.277-299, DOI : 10.24159/joec.2016.22.3.277 